\title{
Problems in learning the Thai language as a foreign language
}

\begin{abstract}
The need for learning the Thai language as a foreign language has shown why this learning is important. Some of the important considerations are the challenges of globalisation, the need to facilitate communication with a society that is using the Thai language, to gain knowledge, for personal use, for social, economic, and political use and to deepen knowledge about the structure of the Thai language. Yet from the research that has been conducted, it has been discovered that there were a few problems faced by the students who are learning the Thai language. This paper will identify the learning problems faced by Thai language students at Universiti Putra Malaysia by using the questionnaires and interview methods. Learning problems are surveyed from the phonology, morphology and syntax aspects. Futher, the research will discuss the appropriate approach to be used to increase the learning of Thai language as a foreign language, the teaching tools, language proficiency aspects that need to be controlled and activities that can be done in order to increase the effectiveness of the education in the Thai language.
\end{abstract}

Keyword: Thai language, foreign language, language learning 